\title{
SUSTENTABILIDADE URBANA E ECOSSISTEMA
}

\author{
Izes Regina de Oliveira ${ }^{1}$
}

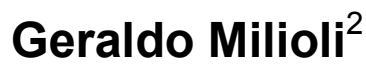

\begin{abstract}
RESUMO
O presente trabalho parte do princípio de que a sustentabilidade urbana está atrelada ao condicionamento dos ecossistemas no que diz respeito às relações e interações entre a sociedade, o desenvolvimento e o meio ambiente. Nesse sentido, contribui ao necessário redirecionamento da questão urbana no mundo moderno apontando alternativas para a permanência dos seres vivos no planeta Terra, como também ao meio ambiente regenerado e regulado para responder aos impactos socioambientais e às mudanças climáticas, de maneira a buscar novas práticas urbanas com bases sustentáveis. Enfatiza a perspectiva sistêmica e a visão ecossistêmica dos assentamentos urbanos e das cidades ao escopo de suas dinâmicas e do alerta da urbanização numa aproximação entre as aglomerações urbanas alternativas existentes e seus equipamentos ecológicos como referência de sustentabilidade. Como resultado, identifica estratégias urbanas ecossistêmicas comparadas ao estudo dos ecossistemas naturais sustentáveis, apresentando estruturas para realizar as mudanças visando à construção da cidade sustentável.
\end{abstract}

PALAVRAS-CHAVE: Sustentabilidade. Ecossistema urbano. Regeneração das cidades.

\section{URBAN SUSTAINABILITY AND ECOSYSTEM}

\section{ABSTRACT}

This paper assumes that urban sustainability is linked to the conditioning of ecosystems with regard to the relations and interactions among society, development and the environment. In this sense, it contributes to the necessary redirection of urban problems in the modern world presenting alternatives to the permanence of living beings on planet Earth, as well as to the environment regenerated and set

\footnotetext{
${ }^{1}$ Arquiteta e Urbanista, Mestre em Ciências Ambientais pela UNESC Universidade do Extremo Sul Catarinense. izesdeoliveira@hotmail.com

${ }^{2}$ Sociólogo, Dr. Professor/Pesquisador do Programa de Pós-Graduação em Ciências Ambientais (PPGCAUNESC) e Coordenador do Laboratório de Sociedade, Meio Ambiente e Desenvolvimento (LABSDMA) da Universidade do Extremo Sul Catarinense - UNESC. Av. Universitária 1105, Bairro Universitário, Bloco P-7, Cx. Postal 3167, CEP 88806-000, Criciúma, Santa Catarina. E-mail geramil@unesc.net
} 
to respond to social and environmental impacts and climate changes, in order to seek new urban practices based on sustainability. It also emphasizes the systemic perspective and the ecosystem view of urban settlements and cities to the scope of their dynamics and the alert for urbanization problem in a rapprochement between the existing alternative urban areas and their ecological equipment as reference to sustainability. As a result, it identifies ecosystem urban strategies compared to the study of sustainable natural ecosystems, showing structures which will allow for the construction of a sustainable city.

KEY-WORDS: Sustainability. Urban ecosystem. Regeneration of cities.

\section{SOSTENIBILIDAD URBANA Y EL ECOSSISTEMA}

\section{RESUMEN}

Este trabajo asume que la sostenibilidad urbana está ligada al acondicionamiento de los ecosistemas con respecto a las relaciones e interacciones entre la sociedad, el desarrollo y el medio ambiente. En este sentido, contribuye a la reorientación necesaria de los problemas urbanos en el mundo moderno que apunta alternativa a la permanencia de los seres vivos en el planeta Tierra, sino también en medio regenerado y ambiente regulado para cumplir con los impactos sociales y ambientales y el cambio climático con el fin de buscar nuevas prácticas urbanas con una base sostenible. Hace hincapié en el enfoque sistémico y la visión de los ecosistemas de los asentamientos urbanos y ciudades en el ámbito de su urbanización dinámica y alerta de enfoque entre las alternativas de áreas urbanas y su Equipo ecológico como referencia la sostenibilidad. Como resultado de ello, identifica estrategias urbanas de los ecosistemas en comparación con el estudio de los ecosistemas naturales sostenibles, mostrando estructuras para hacer los cambios encaminados a la construcción de la ciudad sostenible.

PALABRAS-CLAVE: Sostenibilidad. Ecosistema urbano. Regeneración de las ciudades.

\section{INTRODUÇÃO}

Os problemas socioambientais que a civilização contemporânea enfrenta, associados aos efeitos antrópicos, relacionados à urbanização e ao esgotamento dos recursos naturais que interagem com as mudanças climáticas e a pobreza são complexos e requerem soluções complexas com os princípios ecossistêmicos. Entrelaçados em rede de relações, esses problemas levam a pensar o desenvolvimento atrelado às dimensões social, cultural, ecológica, institucional e econômica.

Por isso, na Cúpula da Terra 2002, Rio+10, os princípios ecossistêmicos e relações socioecológicas foram aspirações que levaram a aprovar os Dez Princípios 
de Melbourne, cujo quinto princípio modela as cidades como um ecossistema sustentável, base deste artigo.

Exemplos urbanos com atenção na direção ecossistêmica salpicam de forma fragmentada e pontual. Assim, a justificativa deste trabalho é formar estratégias para recuperar e renovar as cidades como um todo, reorientar a sociedade e sugerir alternativas para mudanças de ações no tratamento da cidade e da arquitetura para fins da transição para a sustentabilidade. Importa devido à urbanização crescente dos países latinos e do planeta.

O conjunto de informações possibilitará uma proposta política, permitindo subsídios e auxílio aos gestores urbanos, com enfoque na mudança de paradigma, uma vez que os problemas são multidimensionais e interdependentes e refletem a emergente visão sistêmica. Assim, o objetivo é repensar o desenvolvimento para beneficiar mutuamente o homem e a natureza, tratando a cidade à luz do conceito de ecossistema urbano sustentável.

O propósito não é uma exposição exaustiva do conceito de sistemas e ecossistemas, mas caracterizar uma base dos conceitos teóricos acerca da visão sistêmica de Morin (1984, 2001 e 2003) e Capra (2002, 2006, 2006a), unindo a teoria a um crescimento compatível com situações do mundo atual, apontando estratégias propositivas para reconduzir o desenvolvimento urbano e reconstruir cidades com bases sustentáveis.

Após a coleta de dados e análise de conteúdo, o artigo desenvolve um discurso analítico e descritivo, que segundo Chizzotti (2001) propicia uma compreensão qualitativa do tema, neste caso, o ecossistema urbano. Parte dos problemas complexos resultado da pressão que a urbanização do planeta exerce sobre os ecossistemas, reconhece necessária a mudança de paradigma e importa propor uma prática com abordagem ecossistêmica, no todo urbano.

O referencial principal deste artigo é o estudo já realizado "Sustentabilidade Urbana \& Ecossistema: Relações entre a Sociedade, o Desenvolvimento e o Meio Ambiente nos Municípios" de Oliveira e Milioli (2014), entre outros autores. 


\section{BASE DA TEORIA SISTÊMICA E VISÃO ECOSSISTÊMICA}

Construir a sustentabilidade urbana com pensamento sistêmico é aplicar o conhecimento ecológico nas tecnologias, nas estruturas e nas instituições (CAPRA, 2002). Para Capra (2006), sistêmico e ecológico são sinônimos e sua visão da realidade baseia-se na consciência do estado de inter-relação e interdependência essencial de todos os fenômenos físicos, biológicos, psicológicos, sociais e culturais. Por isso sua visão sistêmica é transdisciplinar e aplicada em todos os campos de estudo, transcendendo as fronteiras disciplinares.

Para Morin (2001, p.259) o paradigma sistêmico deveria estar presente em todas as teorias, e campos de aplicação aos fenômenos. Pois o fenômeno sistema é evidente em tudo e a vida é um sistema de sistemas: o ser vivo é um sistema individual, que participa de um sistema de reprodução, que participam de um ecossistema, que participa da biosfera (MORIN, 2003).

\subsection{CARACTERÍSTICAS DOS SISTEMAS}

Base à visão ecossistêmica do urbano e da sociedade.

- O todo: A característica conceitual mais geral que Capra (2006) usa para definir o sistema é a mudança das partes para o todo e aborda as propriedades das partes apenas a partir da organização do todo, envolvido em uma "teia inseparável de relações" dentro de um contexto, por isso o intitula contextual ou ambientalista. Característica complementada por Morin (1984, p. 61) que define o todo como unidade complexa cujas partes têm identidade própria, reconhecidas no todo e o todo nas partes... "o todo é mais que a soma das partes".

- Níveis sistêmicos: O processo de vida é o processo de conhecer, identificado com a cognição. Os organismos mais simples têm mente e são capazes de perceber as mudanças de temperatura, luz e outros. Portanto, têm cognição. As interações de um organismo vivo (planta, animal ou ser 
humano), com o seu meio, em todos os níveis, supera a divisão cartesiana entre mente e matéria, pois envolvem percepção, emoção e ação (CAPRA, 2006).

- Rede de relações: A mudança das partes para o todo surge da rede de relações na organização das partes onde cada função participa da produção ou da transformação dos outros componentes da rede. São dois os principais fenômenos dinâmicos da auto-organização: a autorrenovação que é a capacidade regenerativa que os seres vivos têm de renovar e reciclar seus componentes, e a autotranscendência - que são os processos de aprendizagem, adaptabilidade, desenvolvimento e evolução (CAPRA, 2006). É o que Morin (2001) chama de emergência, cujo fenômeno faz a originalidade do sistema, quando surge uma propriedade nova ou uma qualidade que emerge como um salto lógico. As ações que organizam e transformam elementos ou fenômenos, entre ordem e desordem, Morin (2003, p.72) intitula interação. São transformações que operam sobre as partes, seus antagonismos e suas qualidades emergentes.

- Transformação: quando a organização cria a ordem e a desordem, as transformações energéticas se operam sobre as partes. De certo modo, a organização produz entropia e ao mesmo tempo neguentropia (regeneração do sistema). A desordem está em ação por toda parte, ao mesmo tempo como geradora e degeneradora. A partir dela seguem 0 acaso, 0 acontecimento, o acidente e a criação. Mais rica é a organização, mais ela é rica em desordem.

- Antagonismos: Portanto, a presença e a produção da desordem levam o paradigma da organização a reconhecer incertezas e antagonismos. A ideia de antagonismos, conflitos e contradições, implica potencialidade e anúncio de morte. $O$ aumento da entropia provoca desintegração e dispersão e liberta antagonismos ligados à dinâmica das interações/retroações internas e externas como a bomba $\mathrm{H}$ que integra a maior força de desintegração. Por isso, o sistema evolui no sentido da desorganização (MORIN, 2003). 


\subsection{VISÃO ECOSSISTÊMICA DOS ASSENTAMENTOS HUMANOS E DA CIDADE}

Construir comunidades humanas sustentáveis, baseado no entendimento dos ecossistemas é tomar lições valiosas extraídas do mundo natural. Desta forma Capra (2006) identifica e sugere cinco princípios básicos da ecologia como diretrizes a serem utilizadas:

- Interdependência é a dependência mútua de todos os processos vitais dos organismos. O autor ensina que uma comunidade humana sustentável está ciente das múltiplas relações entre seus membros. Por isso, o comportamento de um elemento depende do comportamento de muitos outros. Para Capra (2006) o sucesso da comunidade vai depender do sucesso de cada membro e vice-versa, por isso a interdependência tem a ver com as relações que determinam as mudanças de percepção, das partes para o todo, de objetos para relações e de conteúdo para padrão, características do pensamento sistêmico. As relações envolvem muitos laços de realimentação, de natureza cíclica, o que leva à reciclagem.

- A lição de Reciclagem e evolução mostrada pela natureza que durante bilhões de anos vem usando, continuamente, as mesmas moléculas de minerais, águas e de ar, poderiam ser usadas nas comunidades humanas (CAPRA, 2006). No fluxo cíclico do recurso, a energia solar aciona a maioria dos ciclos ecológicos, como o aquecimento solar e eletricidade fotovoltaica, o vento, a energia hidráulica, a biomassa, entre outras, que são renováveis, economicamente eficientes e ecologicamente boas para a natureza. Mais uma vez, a natureza demonstra como manter as comunidades humanas sustentáveis, envolvendo laços de realimentação em:

- Parceria e cooperação - são características essenciais que Capra (2006, p. 233) coloca como necessárias para as comunidades sustentáveis. Os intercâmbios cíclicos de energia e de recursos, diz o autor, são sustentados por cooperação generalizada nos ecossistemas naturais. A parceria é tendência para formar associações, estabelecer ligações e certificado de 
qualidade da vida, faz entender as necessidades gerais, propicia a mudança, desafia as atuais estruturas da sociedade e supõe sustentabilidade.

- Interdependência, fluxo cíclico de recursos, cooperação e parceria é o padrão de organização que as comunidades ecológicas necessitam para sobreviver às perturbações externas e se adaptar a condições mutáveis, através da flexibilidade e da diversidade (CAPRA, 2006). Perturbações acontecem durante o tempo todo porque as coisas mudam. A flexibilidade transforma de forma contínua e equilibrada, dependendo da diversidade de religião, habilidades, costumes, nível cultural e etnia, numa comunidade humana. Mais flexibilidade, maiores os limites de tolerância.

\section{NOVE ESTRATÉGIAS PARA RECUPERAR E RECONSTRUIR AS CIDADES}

O entendimento de que a cidade é um sistema complexo permitiu aplicar um dos modelos de Harmut Bossel (1998, apud NEWMAN; JENNINGS, 2008) aplicado às cidades como ecossistemas sustentáveis, a este estudo para ajudar na transição para um desenvolvimento sustentável, dentre um conjunto de outras soluções possíveis.

Estratégia 1 - práticas conectivas que alimentam e sustentam a vida: Todos os membros de uma comunidade ecológica interligados numa vasta e intrincada rede de relações apresentam o princípio sistêmico da interdependência que Capra (2006, p. 23) cita para construir comunidades humanas sustentáveis. Estas relações são as práticas dentro da sociedade, que envolvem a história, a arte, a cultura, os cerimoniais, os rituais, as tradições e a religião que ligam as pessoas entre si e aos elementos da natureza. Isto demonstra a importância do papel da cultura que Morin (1984) diz poder recuperar como expressão a arte, a revolta e a contestação. Estas práticas são herança que perduram como crítica, costume ou religião e fortalecem a relação dos homens entre si e com o mundo. Estas são características de uma sociedade cidadã e ética que fortalece laços sociais e torna uma comunidade saudável e participativa, com plena realização coletiva e individual 
e faz com que as pessoas se sintam parte do lugar e pode ser reforçada a partir do desenho da cidade compacta e de espaços públicos dignos e suficientes.

A Permacultura buscou princípios éticos nas sociedades indígenas baseados no universo da cooperação e da solidariedade para ligar pessoas aos lugares (PAMPLONA, 2005).

Nas ecovilas os contatos diretos ao ar livre, contemplação, jardinagem, hortas, caminhadas, trabalhos de recuperação individual ou comunitários, e ainda, festivais, celebrações, rituais e artes, dão posse à multiplicidade de relações, à complexidade e à flexibilidade de uma comunidade que é outro princípio que Capra (2006) propõe.

Os urbanistas da ecocidade, Register (2008) e Newman (1997), da cidade compacta, Rogers (2001), e o ecólogo urbano Rueda (2000), defendem bairros "caminháveis" e espaços públicos bem elaborados e qualitativos para facilitar as interações e melhorar a convivência.

Estratégia 2 - a visibilidade do mundo "mais humano": a atividade produtora tem efeitos múltiplos, diversos e complexos sobre o ambiente. $\mathrm{O}$ exterior se transforma sob o efeito das ações, das reações, dos produtos e dos subprodutos MORIN (2003), cujos impactos morfológicos urbanos atingem a qualidade ambiental.

O mundo "mais humano" é a nossa responsabilidade sobre as consequências das atividades na dinâmica da cidade e na utilização dos recursos. Newman e Jennings (2008) e Pillet (1993, p. 119) sugerem dar visibilidade aos processos ecológicos para alimentar as conexões, despertando a apreciação ecológica para os recursos naturais água, ar, solo, subsolo, vento, floresta, dos fluxos de energia e dos materiais que apoiam a vida no planeta. Este é o princípio do desenho ecológico. Van der Rynand Cowan (1996, apud NEWMAN; JENNINGS, 2008 , p. 113) acrescenta que tecer a natureza no cotidiano quebra dicotomias destrutivas entre o mundo construído e o mundo natural selvagem. Por isso as cidades sustentáveis são também chamadas de "verdes", pois a biodiversidade e o ecodesign quebram as dicotomias destrutivas. Sugestões de ligar corredores ecológicos com Áreas de Preservação Permanentes - APP, criados para unirem-se, 
aumentam as áreas naturais, fomentam a recuperação dos ecossistemas e a produção alimentícia e dão visibilidade a "um mundo mais humano".

A Permacultura calcula que se cada pessoa cultivasse frutos, verduras, legumes, chás e condimentos em suas janelas, floreiras, terraços, telhados, varandas, sacadas e jardins, em terrenos baldios, parques, canteiros de estradas, gramados, pátios e hortas comunitárias, a produção alimentar na área urbana poderia chegar a 20\%. O sistema permacultural usa recursos biológicos de plantas e animais para realizar trabalhos, melhorar habitats, controlar a erosão, usar a energia passiva e purificar a água. O recurso biológico dos canais de infiltração de Village Homes, Davis - Califórnia drena e direciona suas águas superficiais e repõe $90 \%$ das águas subterrâneas, evitando enchentes, recompondo a natureza do ecossistema aquático, biológico e animal, resultando em economia (MOLLISON; SLAY, 1994).

\section{Estratégia 3 - proteger a diversidade cultural, econômica e ecológica: o} modelo de ecossistema urbano sustentável fundamentado no saber ambiental abre estratégias de poder no saber e no conhecimento científico e põe à vista a economia como um novo objeto interdisciplinar cuja produção econômica, no pensamento de Leff (2010), deve ser redefinida e fundamentada entre os potenciais ecológicos, a produtividade tecnológica e a criatividade cultural. Essa nova economia tem valores culturais e "Cada cultura dá significado a seus conhecimentos, a seus saberes, a sua natureza, recriando-a e abrindo o fluxo de possibilidades..." (LEFF, 2010, p.91).

Para Capra (2006) a diversidade cultural, ecológica e econômica está estreitamente ligada com a estrutura da rede do sistema e reafirma a interdependência entre os indivíduos, sociedade e natureza e o todo integrado aos processos cíclicos da natureza.

A proteção da diversidade cultural, econômica e ecológica é crucial para a resiliência dos sistemas urbanos, por isso o ambiente histórico e as culturas tradicionais devem ser reconhecidos como fonte de sabedoria para modos de vida sustentáveis. A diversidade econômica oferece opções para a mudança e assegura a resiliência do sistema urbano da mesma forma que lida com os ciclos econômicos 
de expansão e contração (MOLLISON; SLAY, 1994, p. 193; NEWMAN; JENNINGS, 2008, p. 114).

Ao proteger, recuperar e criar parques, bosques e corredores ecológicos cria-se uma rede de reservas que aumenta a biodiversidade do município e biorregião. Esta rede ajuda a manter os serviços vitais do ecossistema como aumento da qualidade e quantidade de água, melhoria do ar e proteção do clima, captação de gases de efeito estufa, suprimento de parte das necessidades alimentares da comunidade e ainda, reconhece a interdependência cultural, econômica e ecológica. Esta interdependência propõe um fluxo cíclico de recursos em cooperação e parceria cujo padrão de organização é proposto por Capra (2006) e deve integrar decisões para que as ações dos gestores atendam a todas as áreas que as comunidades ecológicas necessitam para sobreviver às perturbações externas e se adaptar a condições mutáveis onde cada função participa da produção ou da transformação dos outros componentes da rede na organização das partes (CAPRA, 2006).

Estratégia 4: economia local e biorregional de sustento: as tecnologias de informação e a globalização vêm alterando as relações das cidades, com economia fora da sua biorregião. Grandes entradas para o ecossistema urbano das cidades drenam recursos seus e de outros ecossistemas (ODUM, 2004). Para que as cidades adquiriram características sustentáveis, a energia deve ser adquirida no nível local como a solar e outras fontes no nível biorregional (NEWMAN; JENNINGS, 2008). Além disto, as necessidades básicas para a sobrevivência humana, de alimento e água devem caber na capacidade do bioma. Pois a cidade sustentável é a que está em equilíbrio com sua paisagem e vive do lucro líquido ecológico da sua região de apoio (BERRY, 2000 apud NEWMAN; JENNINGS, 2008).

Assim, para restabelecer a capacidade do ecossistema as necessidades de consumo devem ser cumpridas mais perto do ponto de produção (CAPRA, 2006). A Permacultura ensina que a distancia deve estar por volta dos $100 \mathrm{~km}$, no máximo, e a ecovila se apropria da escala com base na residência e no local que fazem parte de uma economia de comunidade. 
Muitos autores sugerem altas densidades, pois a concentração de pessoas favorece as atividades econômicas como comércio e serviço a nível local, maximizando inclusive o uso da infraestrutura existente. Como a cidade compacta de Rogers (2001) cujo zoneamento multifuncional reduz deslocamentos e dá ênfase ao transporte público, que reduzindo a necessidade de viagens, encoraja o pedestrianismo e o ciclismo e aumenta os espaços públicos.

Estratégia 5: energia solar e arquitetura ecológica: as atividades ligadas à construção civil consomem cerca de metade da energia produzida, tanto para a produção de materiais e transporte, quanto para a energia gasta no conforto da vida.

O consumo através de fontes renováveis de energia solar, eólica, ou biocombustível ou outra energia local, se desvinculam da dependência energética externa. Por isso a arquitetura na contemporaneidade precisa mudar o conceito para bioecológica, utilizando formas passivas para diminuir os gastos energéticos. Desta forma o conceito de arquitetura dado por Vitruvio de utilidade, beleza e solidez, na contemporaneidade passa a ter mais um vértice, o da eficiência energética (LOTZ, 1991).

Muito embora ainda sejam limitados os esforços em produzir edificações energeticamente eficientes, que aproveitem melhor os recursos naturais de iluminação e climatização, que usem materiais locais sem impacto ambiental, ou materiais reciclados e recicláveis a arquitetura contemporânea precisa integrar o conhecimento ecossistêmico como sugerem Sattler (2009); Lotz (2007) e Bueno (1995). Estes conhecimentos muitas vezes são técnicas antigas, como o uso da terra crua para o fechamento de paredes, do telhado verde para o conforto termo acústico, uso dos materiais locais, captação das águas da chuva, reutilização das águas servidas, reciclagem total dos resíduos, energia solar passiva e outras adaptações específicas às condições locais de clima, orientação de ventos, índice pluviométrico e umidade do ar, necessários para um urbanismo e uma arquitetura sustentáveis.

A arquitetura do século XXI devem se inspirar na natureza, como a arquitetura de Frank Lloyd Wright, e será tão mais interessante e inteligente se incluir, definitiva e categoricamente, o projeto ecológico total na sua concepção. 
Estratégia 6 - design sustentável dos sistemas de apoio: todo ser aberto, como a cidade e os indivíduos, age e retroage em seu ambiente, por isso tem "uma identidade própria e uma identidade de dependência ecológica que os liga a seu ambiente" (MORIN, 2003, p.252, 253).

Assim a necessidade vital de energia, alimentos, ciclagem de nutrientes e purificação da água e do ar nos torna dependentes da saúde dos ecossistemas, por isso a proteção da biodiversidade é crucial à sobrevivência humana (MAB, 2010).

Autores da visão sistêmica afirmam que os ecossistemas sustentáveis tem que ser saudáveis, autorreguláveis, autorrenováveis, resilientes, flexíveis e sem resíduos como qualquer ecossistema natural. Por isso, o ecossistema urbano sustentável, necessita design sustentável para os sistemas de apoio - produção de energia, tratamento do esgoto e águas superficiais, reciclagem de resíduos, captação da água e o transporte.

Como é necessário reduzir $80 \%$ das emissões de CO2 até 2050 , o argumento da arquitetura e urbanismo contemporâneos é tecnologia ecológica e barata, uso de materiais disponíveis localmente e design sustentável e acessível a todos, como nos exemplos abaixo:

Rogers (2001 apud GIRARDET, 1999) propõe adotar um metabolismo circular (fig. 1) onde a cidade minimiza entradas, usa fluxos de energia e recursos renováveis, recicla todos os materiais (papel, vidro, metais, e plásticos), reutiliza as águas, e composta resíduos orgânicos, tudo dentro dos limites locais e regionais. 


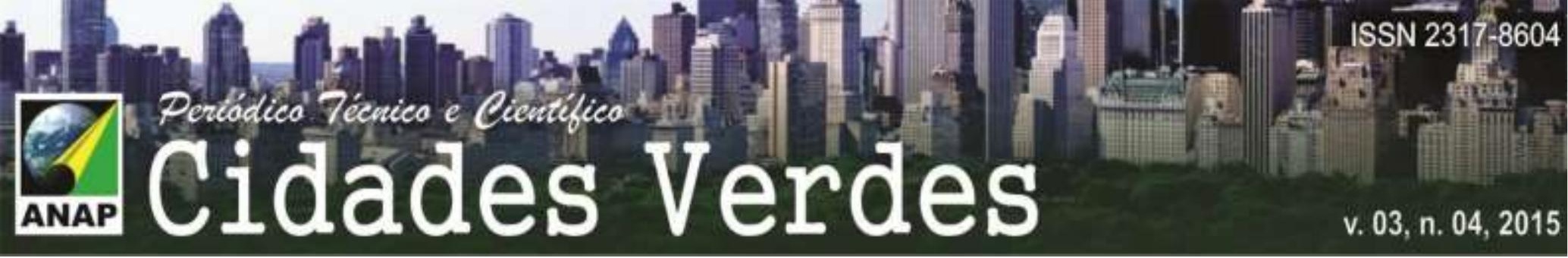

Figura 1: Metabolismo Circular

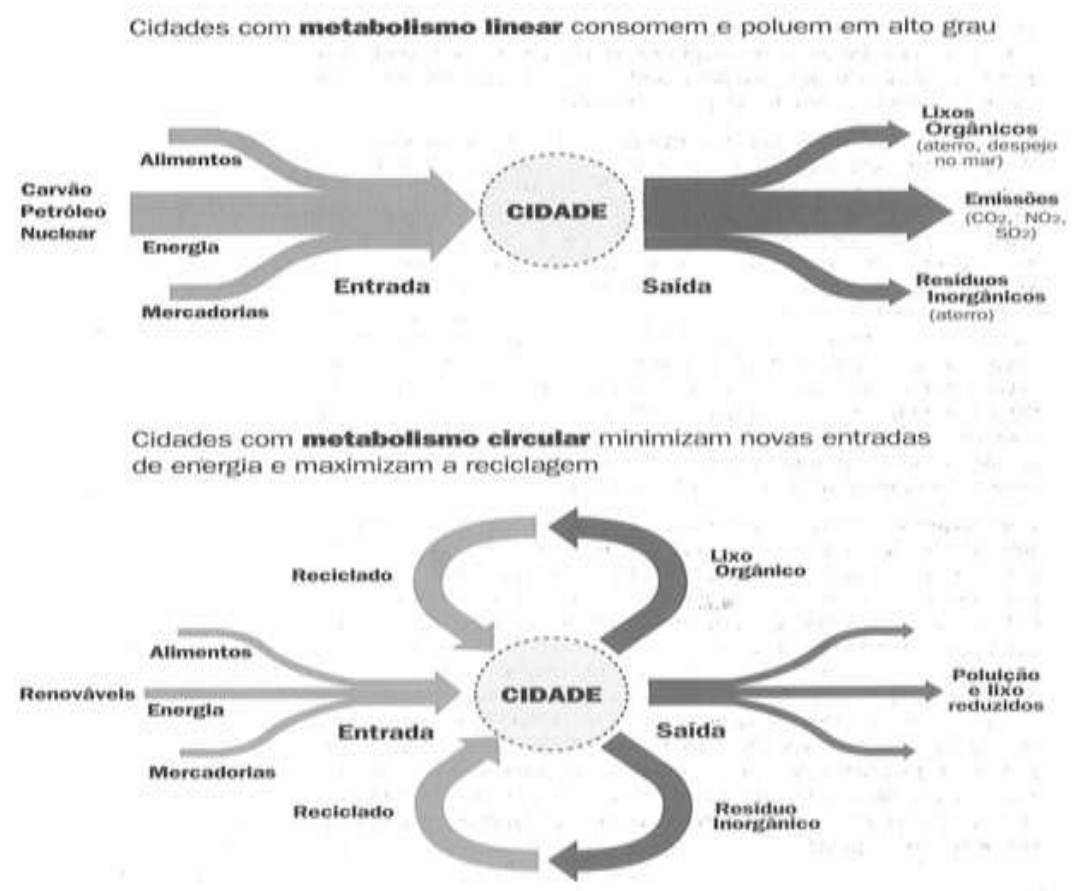

Fonte: HERBERT GIRARDET apud Rogers, 2001.

Os princípios da concepção ecológica, o biomimetismo - imitação da natureza, a Permacultura e o design regenerativo são moldados à natureza humana. Capra (2002, p. 241) diz que o sentido é aprender com a natureza que é infinitamente superior à ciência humana. Ele sugere os agrupamentos industriais ecológicos "ZERI" (Zero Emissions Research and Initiatives) - empresas com zero resíduo e zero desperdício, estabelecidos em diversas partes do mundo. Estas cooperativas usam o conhecimento da biodiversidade com processos ecológicos de forma que o recurso de uma empresa é o subproduto de outra, dentro do mesmo tecido urbano. Aumentam a produtividade e a qualidade dos produtos com o uso da energia solar, reciclam materiais após consumo, em ambiente livre de poluição e resíduos tóxicos.

A Permacultura reutiliza águas residuais num ciclo sistêmico e retém águas pluviais como nos estudos sistêmicos do engenheiro Carlos Tucci que propõe reter e deter águas superficiais para prevenir enchentes; a literatura mostra exemplos de transformação urbana a partir da renaturalização de córregos e rios, despoluição por biorremediação, prevenção de enchentes com reintrodução da biodiversidade. 
Exemplos para reter as águas superficiais são os Jardins de Chuva, os telhados jardins, a pavimentação permeável - ecodreno, petit pavê...

A sustentabilidade é projeto coletivo e requer apoio generalizado. Newman e Jennings (2008), Santos (2001) e Jacobs (2001) falam da oportunidade que a concentração de pessoas traz para a participação nas comunidades, possibilitando a pesquisa integrada quanto aos sistemas de apoio. Supõe-se, desta forma, capacitar e mobilizar pessoas, para conhecerem os recursos locais e se envolverem nas decisões que os afetam Newman e Jennings (2008, p. 120). Com a escassez dos recursos, deveremos investir mais nas pessoas, que é recurso abundante (CAPRA, 2006).

Estratégia 7 - gestão adaptativa de instituições policêntricas: O nível da escala com o critério das dimensões humanas está ficando cada vez mais importante, no que diz respeito a estruturas, organizações e empresas. "O que é vasto, rápido ou congestionado demais, em comparação com as dimensões humanas, é grande demais" (CAPRA, 2006a, p. 388).

Um ecossistema urbano sustentável está intimamente ligado à manutenção do fenômeno urbano em escalas controláveis e a valorização da escala local.

Capra (2006a, p. 389) afirma que os governos centralizados "não são capazes de atuar localmente nem pensar globalmente". Por isso, a descentralização política e o desenvolvimento regional são necessidades urgentes que devem incluir a cooperação e a parceria para incentivar a gestão comunitária, enfatizar a inclusão e contribuir com as carências das populações quanto à redistribuição da produção de alimentos e a partilha de conhecimentos. Pois um ecossistema urbano sustentável está psicologicamente compromissado com o desejo das pessoas.

O reconhecimento da integração harmoniosa com o planeta e seus múltiplos sistemas auto-organizadores leva à ética planetária e às novas formas de organização (CAPRA, 2006a, p. 389). Por isso, o Estatuto da Cidade propõe a participação descentralizada como as conferencias e os conselhos, entre outros exemplos de descentralização do poder como as experiências democráticas brasileiras dos Orçamentos Participativos, dos Congressos das Cidades e da Conferencia Nacional das Cidades, oferecida pelo Ministério das Cidades. 
paradigma ecológico inclui "uma mudança na organização social, uma mudança de hierarquias para redes" (CAPRA, 2006, p.28).

Estratégia 8 - o bairro e a renovação urbana: para que os processos ecológicos se tornem viáveis novamente a proposta de Newman (1996) é a regeneração à pequena escala, ao nível de vizinhança, para que as pessoas possam se reconectar entre si. Semelhante à ecocidade de Register (2006) que propõe a recentralização física para transformá-la em comunidades menores com acesso aos pequenos centros comerciais de vizinhança para pedestres e ligados por ciclovias.

A regeneração das cidades bate no conceito de resiliência o qual se aplica melhor à escala do bairro e, em certa medida, ao caráter econômico de uma cidade. É uma tendência velhos centros industriais se renovarem e se transformarem em novas indústrias, baseadas no conhecimento de regeneração de suas cidades ou áreas abandonadas e vazias se reconverterem em bairros criativos. A recuperação do rio Cheonggyecheon, de Seul e a revitalização do seu entorno é a renovação urbana mais famosa deste início de século que reincorporou o espaço da autoestrada ao público e à cidade. Existem na literatura exemplos importantes de renovação urbana com substituição de vias e elevados por parques urbanos e recuperação de rios integrados a metas ecológicas, recreação e requalificação de espaços públicos.

Estratégia 9 - promover a cooperação através de parcerias: a sustentabilidade é busca coletiva e as parcerias são fundamentais para capacitar as funções sociais e econômicas em todas as escalas ecossistêmicas. Morin (2003) propõe que a transformação seja mútua, como nos sistemas naturais que tiram do ambiente, mas dão algo de volta.

Para construir comunidades humanas sustentáveis, baseadas no entendimento dos ecossistemas, a parceria e cooperação são características essenciais. Para cooperar, a tendência é formar associações, estabelecer ligações e desenvolver a democracia e o poder pessoal (função social) (CAPRA, 2006) como a ecovila que certifica a qualidade de vida. 
Existem vários movimentos parceiros das cidades, na escala global, como o programa "Cidades para a Proteção Climática e o Desafio da Água", patrocinado pelo Conselho Internacional para Iniciativas Ambientais Locais (ICLEI). Cidades brasileiras associadas a este programa: de Belo Horizonte e Betim - MG e Porto Alegre - RS.

Seguindo o modelo cooperativo e de parceria como nos ecossistemas naturais e sistemas sustentáveis socioecológicos, os projetos humanos podem ser transformados para nutrir as necessidades não só dos humanos, mas também das outras formas de vida, contribuindo para um círculo mais amplo (NEWMAN; JENNINGS, 2008, p. 122).

A individualização da sociedade é o oposto da parceria, à qual é necessário criar uma cultura rumo à sustentabilidade através de informação.

\section{CONCLUSÃO}

O alerta da urbanização fortalece o paradigma sistêmico. Este trabalho reconhece o conjunto de relações complexas que atuam no ecossistema urbano seja a sociedade, a cultura e a forma da economia e não somente os valores próprios da natureza, por isso aposta na abordagem ecossistêmica para conter o processo de degradação, melhorar a qualidade de vida e aumentar a resiliência do ambiente para combater a alteração climática. Registra, assim, um conjunto de ações estratégicas para tornar a cidade um ecossistema urbano sustentável.

Uma mudança paira no ar e desafia o pensamento tradicional. Enquanto ela não acontece, um movimento silencioso, consciente e ético está iniciando este processo, com projetos positivos, usos e atitudes alternativas, diferenciadas e inovadoras. Muito embora a sociedade seja simpática ao desenvolvimento sustentável há necessidade de disponibilizar os meios para que aconteça, pois o caminho é complexo e longo e passará inevitavelmente pela cidade. Compreender as necessidades para a transição da sustentabilidade viabiliza a aplicação das estratégias apresentadas. Estas mostram uma forma de viver coletivo integrado com a natureza, reafirmam o pensamento de mudança e incorporam o ensinamento dos 
PAMPLONA, Sérgio. O que é permacultura. In: Revista Permear: soluções para a sustentabilidade. Brasília: Teixeira, fev./mar. 2005 \# 1.

PILLET, Gonzague. Economia ecológica: introdução à economia do ambiente e recursos naturais. Lisboa: Divisão editorial: Instituto Piaget, 1993.

REGISTER, Richard. Eco Cities: making cities sustainableis a crucial challenge. Copyright (c) 1985 atualizado (2008). Disponível em: <http://www.context.org/ICLIB/IC08/Register.htm>. Acesso em: out. 2009.

ROGERS, Richard et al. Cidades para um pequeno planeta. Barcelona: Gustavo Gilli, 2001.

RUEDA, Salvador. Modelos de ciudad: indicadores básicos. Quaderns d'arquitectura i urbanisme. Barcelona, n. 2000, p.25-32, 2000.

SATTLER, Miguel Aloisio. Estratégias bioclimáticas de reabilitação ambiental adaptadas ao projeto. in: Reabilitação ambiental sustentável arquitetônica e urbanística/ Marta Adriana Bustos Romero, org. Brasília: FAU/UnB, 2009.

TUCCI, Carlos E. M. Gestão de águas pluviais urbanas/- Ministério das Cidades - Global Water Partnership - World Bank - Unesco, 2005. Disponível em: file:///C:/Users/User/Downloads/gestaodeaguaspluviais.pdf acesso em abril de 2014. 